\title{
Rebelión social en la ciudad Notas sobre significaciones políticas del octubre chileno
}

\author{
Social rebellion in the city \\ Notes on political significations of Chilean October
}

Marcelo Rodríguez-Mancilla

Universidad de Playa Ancha, Chile marcelor26@yahoo.es https://orcid.org/0000-0003-3982-3736

Roberto Vargas-Muñoz

Universidad Alberto Hurtado robertovmu@gmail.com https://orcid.org/0000-0002-6041-9351

Paulo Contreras-Osses

Universidad Alberto Hurtado pcontreras@uahurtado.cl https://orcid.org/0000-0003-1363-7679

Rodolfo Quiroz-Rojas

Universidad Alberto Hurtado rodolfoqr@gmail.com https://orcid.org/0000-0003-3531-4790

Forma sugerida de citar: Rodríguez-Mancilla, M., Vargas-Muñoz R., Contreras-Osses, P., \& QuirozRojas, R. (2020). Rebelión social en la ciudad. Notas sobre significaciones políticas del octubre chileno. Universitas, 33, pp. 201-224. 


\title{
Resumen
}

En este ensayo se proponen algunas notas sobre las significaciones políticas de la rebelión social, ocurrida a partir del 18 de octubre del año 2019 en diversas ciudades de Chile. Se argumenta que el actual escenario de movilizaciones es una respuesta al proceso histórico de neoliberalización de la sociedad chilena. Entre las características más importantes de esta rebelión, se encuentra la diversificación de los usos políticos del espacio urbano y la reapropiación subalterna de la articulación social en la ciudad. Este proceso intensifica y extiende la conflictividad social producto de la profundización de las contradicciones del patrón de acumulación de capital impuesto en la dictadura cívico-militar, y muestra el agotamiento del Estado subsidiario y de la democracia semi-soberana. A partir de un análisis de coyuntura, complementada con la descripción de los principales ciclos de movilizaciones sociales en el espacio urbano desde la segunda mitad del siglo XX, se sostiene que la actual rebelión social evidencia, parcialmente, la ruptura del consenso neoliberal, la politización de lo social y el fortalecimiento del poder local en las ciudades. Se concluye que lo novedoso de la rebelión social es la intensidad, amplitud y diversificación de formas y contenidos del ejercicio político de diversos sectores sociales y territoriales.

\section{Palabras clave}

Rebelión social, neoliberalización, ciudadanía, politización, poder local, Chile.

\begin{abstract}
This essay proposes some notes on the political significations of the social rebellion which occurred in several Chilean cities on October 18th, 2019. It is argued that the current scenario of mobilizations represents a reaction to the historical process of neoliberalization of Chilean society. Among the most important characteristics of this rebellion is the diversification of the political uses of urban space and the subaltern reappropriation of the social articulation of the city. This process intensifies and extends the social conflict resulting from the deepening of the contradictions of capital accumulation's pattern imposed by the civic-military Dictatorship, and shows the exhaustion of the subsidiary State and semisovereign democracy. Based on an analysis of the political climate, complemented by the description of the main cycles of social mobilizations in urban space since the second half of the 20th century, it is argued that the current social rebellion partially evidences the breakdown of the neoliberal consensus, the politicization of the social and the strengthening local power in the cities. It is concluded that the novelty of social rebellion relies on the intensity, breadth and diversification of forms and contents of the political exercise of diverse social and territorial sectors.
\end{abstract}

\section{Keywords}

Social rebellion, neoliberalization, citizenship, politization, local power, Chile.

\section{Introducción}

\author{
El 18 de octubre de 2019 da inicio a un fenómeno de rebelión social \\ inédito en magnitud e intensidad en la historia de Chile. Este fenómeno ha
}


suscitado un importante flujo de reflexiones en busca de su significación. La consigna que se escucha habitualmente en las calles es "Chile despertó". Pero, ¿de qué despertó? Al parecer hay un cierto consenso de que este despertar resulta del desgaste de los procesos de neoliberalización de la sociedad chilena, que ha estado sumergida en un profundo sueño inducido por la utopía del mercado abierto, desregulado y competitivo, en tanto mecanismo idóneo para el desarrollo económico y la integración individual. Utopía que de facto ha tenido éxito en el continuum del patrón de acumulación capitalista en países periféricos como Chile, pero que se interrumpe por la erupción de su propia contradicción. Esto es, la incapacidad, por definición, de construir una sociedad más democrática, igualitaria, y garantista en derechos sociales que efectivice mejoras sustanciales en la vida cotidiana de la ciudadanía y sus territorios.

En este sentido diversas aristas explicativas han movilizado las reflexiones. Se ha afirmado que presenciamos una sistemática crisis de representación política, ligada fundamentalmente al descrédito y la desconfianza hacia la élite política (Salazar, 2019; Garcés, 2019). Ello expresa una crisis del sistema de democracia restringida, tutelada y de baja intensidad desde 1990, reflejada en una continua disminución de los patrones electorales (Grez, 2019). Desde 1991 el Programa de Naciones Unidas para el Desarrollo (PNUD) venía registrando una significativa desconfianza de la ciudadanía $(54 \%)$ frente al Estado, los partidos políticos y los políticos. Entre 2017 y 2019 las cifras fluctúan entre $80 \%$ y 95\% (Salazar, 2019). Por otro lado, estamos ante la exacerbación del malestar social inducido por la creciente desigualdad social que ha fracturado a la sociedad chilena (Matus, 2019), y las nuevas expectativas generadas a partir de un proceso de mayor escolarización y formación universitaria (Araujo, 2019).

Al revisar el espectro de reflexiones contingentes de la rebelión social (Araujo, 2019; Folchi, 2019; NEMESIS, 2019), constatamos que los análisis de coyuntura que recurran a aspectos históricos y territoriales han sido escasos. En esta línea, postulamos que la rebelión social es una respuesta al proceso de neoliberalización de la sociedad chilena con una particular y novedosa intensidad. Se trata de una diversidad de usos políticos, sociales y culturales del espacio urbano y una disputa por la reapropiación subalterna de la articulación social en la ciudad. Ello implica una recomposición geopolítica de la vida cotidiana, en tanto reconquista del espacio urbano por las masas autoconvocadas, y una disputa simbólica por la re- 
presentación política del malestar social; que antagoniza directamente con el rol del Estado subsidiario y una democracia restringida. En suma, la rebelión social da cuenta de un triple movimiento: la ruptura del consenso neoliberal, la politización de lo social y el fortalecimiento del poder local en la ciudad.

Para desarrollar este argumento, describimos, en primer lugar, un marco contextual de los cinco ciclos de rebeliones sociales más importantes que se han documentado desde 1938 hasta 2016. Realizamos el corte temporal en 1938, porque es a partir de allí que es posible situar un ciclo de transformaciones políticas, sociales y económicas, que ayuda a entender el primer reventón histórico en la ciudad en 1957, el cual se gatilló, al igual que la rebelión de octubre del 2019, por la subida del precio del transporte público. Las dos primeras revueltas, las graficamos por medio de un mapa a escala nacional, que se elaboró con base en el libro "Violencia política popular en las grandes alamedas. La violencia en Chile 1947-1987" de Gabriel Salazar (2006). En él se presentan tres escenarios históricos, cuya principal distinción radica en un cuadro de doble dinámica que relata los hechos de agitación social escénicamente determinados y, al mismo tiempo, se establecen sus tendencias proyectivamente determinantes. Los otros dos ciclos se mapean gracias a la revisión y recopilación de archivos de prensa digital nacional-local, a partir de la cual se procedió a la espacialización de los hotspot de las movilizaciones estudiantiles y regionalistas-ambientalistas en las principales ciudades de Chile. En segundo lugar, narramos el devenir de los principales acontecimientos conflictivos que se suscitaron en la rebelión social del octubre chileno. Nos apoyamos con un mapa a escala nacional que se elaboró a partir de una revisión exhaustiva de más de 350 registros de prensa digital de las principales capitales regionales y provinciales, según la cronología diaria de las protestas. Y, en tercer lugar, relacionando los elementos histórico-contextuales con la rebelión de octubre, ensayamos algunas razones y conceptualizaciones sobre las significaciones políticas de la rebelión social, destacando la emergencia de nuevas estrategias de ejercicio del poder local en las ciudades, como aspecto más novedoso e interesante a discutir de cara al eventual e inédito proceso constituyente chileno. 


\section{Rebeliones sociales en Chile entre 1938 y 2016}

En Chile, la segunda mitad del siglo XX está cruzada por episodios violentos, conocidos como "reventones históricos", en sus más variadas formas y expresiones geográficas. Hubo una reproducción cíclica de sucesos de violencia política popular en el espacio urbano que ha tensionado la institucionalidad vigente, junto con un contramovimiento represivo del Estado, como táctica para "devolver a la fiera histórica a su jaula" (Salazar, 2006, p. 51). Durante los últimos ochenta años de vida política (Salazar, 2006; Milos, 2015; De la Maza \& Garcés, 1985; Mayol \& Azócar, 2011; Valenzuela et al., 2016), es posible identificar cinco grandes ciclos de movilizaciones en las ciudades: 1) composición y descomposición del nacional-desarrollismo (1938-1958); 2) recomposición y crisis del nacional-populismo (1958-1973); 3) jornadas de protesta nacional contra Pinochet (1983-1986); 4) movilizaciones del sector educacional (2001-2011); y 5) movilizaciones ambientalistas y regionalistas (2009-2016) (ver imagen 1).

El primer ciclo de movilizaciones se inscribe en el proceso de consolidación democrática y de industrialización sustitutiva del Estado (1938-1958). En este periodo emerge un nuevo actor social que dejó atrás al empresariado nacional articulado a los capitales y casas comerciales británicas. Debido a las consecuencias de la primera guerra mundial y la crisis de la década del 1930, el empresariado tecnocrático-fiscal entró en escena para construir la noción del Estado empresarial o fabril. Este proceso, según Salazar (2006), presentó contradicciones pues el Estado empresarial fue menos autónomo y eficiente de lo que fue su antecesor. Por lo tanto, se administró políticamente el desplazamiento y agudización de las tensiones entre actores, adoptándose una relación clientelar de los movimientos políticos. Hubo, por ende, una subsunción en "electorado nacional" sin contenido social.

En el segundo gobierno de Ibáñez del Campo, la crisis económica implicó efectuar un giro del nacional-desarrollismo a uno librecambista. Ello derivó en un aumento de los precios, la disminución de la productividad industrial e inflación. Así, el alza entre un 50\% y $100 \%$ de la tarifa del transporte público gatilló el primer reventón histórico en abril de 1957, que se extendió por Valparaíso, Santiago y Concepción (ver imagen 1). Doce días duró la movilización con más de una veintena de muertos, centenares de heridos y cuantiosos destrozos materiales. Este reventón expresó un reclamo generalizado respecto de una ruptura más profunda de la sociedad: aquella 
entre quienes estaban o se sentían integrados a la vida social y aquellos que estaban o se sentían marginados de ella (Milos, 2015).

El segundo ciclo de movilizaciones (1958-1973) tuvo como escenario una crisis del Estado, principalmente de la clase política civil gobernante. Para enfrentar los problemas del modelo dependiente del mercado mundial, a merced de su vocación primario-exportadora, se aplicó el recetario liberal en lo político y lo social. Es por ello que Salazar (2006) hace referencia a este periodo como una segunda oportunidad para el capitalismo mercantil, pero bajo otro tipo de prácticas, como la planificación y la participación social, que permitieron satisfacer el imperativo de la modernización.

Los reventones entre 1960-1968 transformaron las formas de lucha del movimiento de masas: de las huelgas funcionales en industrias y otros sectores productivos que coparon los primeros años (Mademsa, Madeco, metalúrgicos, mineros del carbón, Compañía Chilena de Electricidad, entre otras), se pasó a formas de ocupación y control territorial. Es decir, fueron principalmente tomas de fábricas y tomas de terreno las expresiones de mayor relevancia, y que en 1968 disputan a partir de acciones concertadas por diversos grupos sociales del bajo pueblo.

El tercer ciclo de movilizaciones comprende las Jornadas de Protesta Nacional contra la dictadura de Pinochet entre 1983 y 1986. Según diversos autores (Delgado \& Maugard, 2018; Hunneus, 2016; Valdivia et al., 2012) este ciclo de manifestaciones demostró la derrota social del régimen, una vez que los centros de disputa política se concentraron en las poblaciones y sectores populares, manifestando su descontento y "poniendo en juego incluso la estabilidad misma del régimen” (Delgado \& Maugard, 2018, p.35).

Dichas protestas irrumpen en el escenario urbano a raíz de la profunda crisis económica por la cual atravesaba Chile entre 1981 y 1982. La banca prácticamente quebró, la deuda externa era insostenible, además de niveles de inflación y desempleo que bordeaban entre el 10\% y el 20\% (De la Maza \& Garcés, 1985). Esta crisis, sumado a la dura represión y violencia política de más de diez años de régimen autoritario, generaron condiciones para la politización social y la emergencia de la protesta en las ciudades con una amplia participación de los sectores populares.

Casi dos décadas después, ubicamos el cuarto ciclo de movilizaciones. Desde el 2001 al 2011 sucedieron protestas de alta recurrencia ligadas al sector educacional, las cuales tensionaron el pacto neoliberal en democracia. Este tipo de movilizaciones se caracterizó por la ocupación del espacio 
público vía marchas y concentraciones en lugares estratégicos de la ciudad, además del control y ocupación masiva de los recintos escolares y universitarios, lo que muestra una mayor capacidad orgánica y radicalidad.

La primera movilización estudiantil fue conocida como el "mochilazo" el año 2001, momento en el cual las y los secundarios lograron frenar la subida del pase escolar y extender el beneficio durante todo el año. La segunda asonada estudiantil, "La Revolución Pingüina” del 2006, inauguró la legitimación de la protesta de masas, pues fue apoyada por vastos sectores de la sociedad chilena. Situación que será amplificada por el movimiento universitario del 2011 que copó las calles y plazas del país con más de 200 mil personas, desarrollando performances urbanas (corridas, besatones, coreografías, etc.), uso de redes sociales y ocupaciones universitarias.

El quinto ciclo de movilizaciones ambientalistas y regionalistas (20092016) evidencia "la construcción de discursos favorables a la autonomía política y a la coparticipación en los ingresos que se producen territorialmente" (Valenzuela et al., 2016, p. 226). Al menos tres factores explican el ciclo de estas protestas: la producción de desigualdades socio-territoriales entre regiones; las consecuencias de la devastación ambiental generada a partir de los principales sectores productivos primarios; y el escaso retorno de plusvalía hacia las comunidades y territorios, desde donde son extraídas las mercancías. Todo ello, integrado al hecho de que los principales partidos políticos pasaron a ser elites oligárquicas, que no canalizaron las demandas de la ciudadanía (Valenzuela et al., 2016).

De este modo, según muestra el mapa (ver imagen 1), son al menos dieciséis las ciudades de Chile que han tenido movilizaciones durante el último decenio. Por ejemplo, uno de ellos corresponde al conflicto suscitado en la ciudad de Calama durante el 2009 producto del alto valor del cobre, el cual derivó en el desarrollo de un petitorio: a) recuperación del 5\% de utilidades del cobre en zonas productoras; b) compensación por traslado del campamento de Chuquicamata; c) declaración de Calama como zona extrema; d) compensación de 400 millones de dólares por los 34 años en que la ciudad no ha tenido las utilidades del cobre; e) renacionalización de los recursos cobre y agua.

Los cinco ciclos de movilizaciones antes descritos representan una disyuntiva histórico-estructural entre la tendencia a la mercantilización de la vida cotidiana, que resulta del modelo económico-social dominante y sus diferentes crisis políticas, sociales y ambientales; y la necesidad de dignifi- 
car la vida y garantizar derechos sociales. Ha sido por medio de diversas formas y contenidos de politización social y reapropiación urbana y territorial de grupos subalternizados, que se han consolidado las movilizaciones, las cuales son cada vez más intensas y extensas, y muestran una ampliación de la conciencia social sobre la desigualdad estructural de la sociedad chilena.

\section{Imagen 1}

Mapa nacional según ciclos de movilización social en Chile 1938-2016
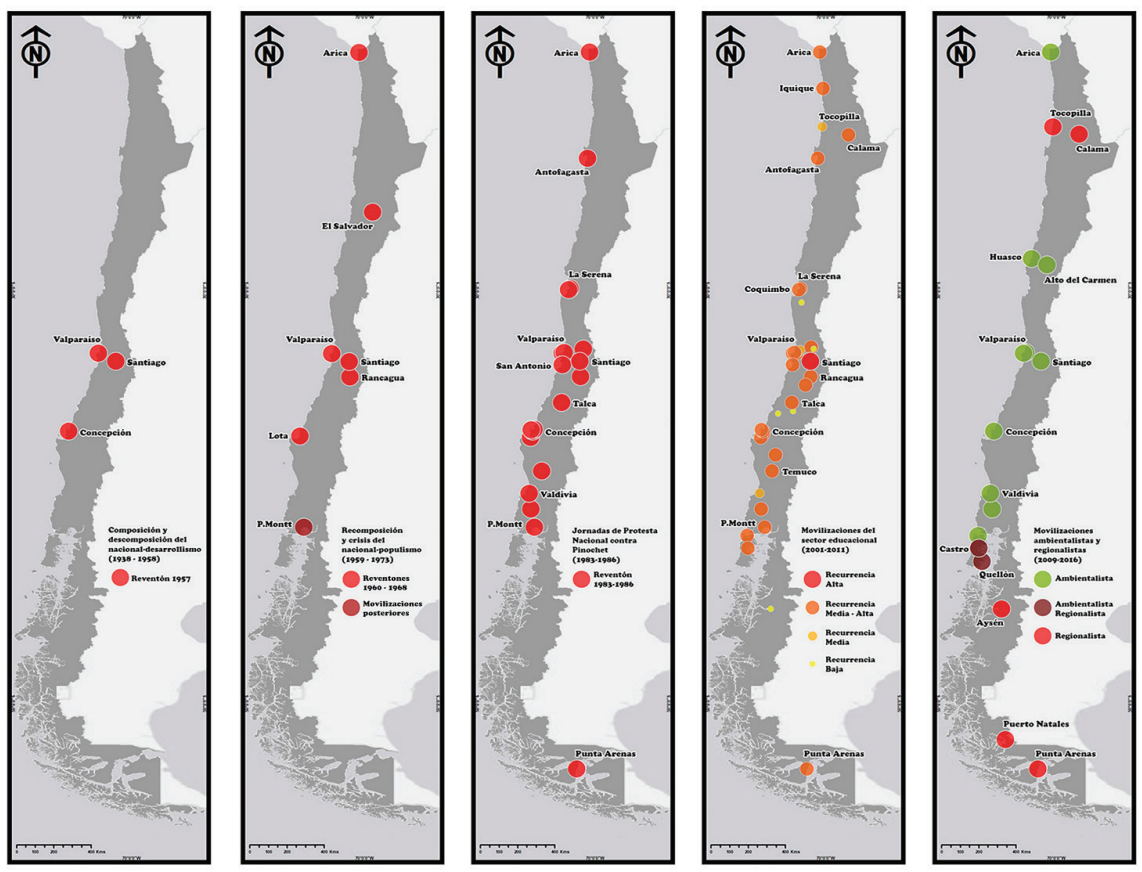

Fuente: Elaboración propia.

\section{Una narrativa de la rebelión social del octubre chileno}

El 14 de octubre del 2019 se inician protestas lideradas por estudiantes secundarios producto del alza de 30 pesos en el valor del pasaje del metro de Santiago, mientras que la elite política, con una actitud despótica, llama a 
la ciudadanía a "levantarse más temprano" para pagar menos, puesto que las tarifas de precios son diferenciadas según horario. Frente a esta situación, la perseverancia de las y los estudiantes junto con la consigna "evadir, no pagar, otra forma de luchar”, parece aunar una energía social más allá de lo usual. Pasado el mediodía del viernes 18 de octubre, las principales estaciones del metro son suspendidas y todo el sistema de inter-buses colapsa. Miles de trabajadoras, trabajadores y estudiantes deben caminar forzadamente desde el centro de la ciudad a sus respectivos hogares, a las periferias y comunas colindantes, en donde se van articulando múltiples barricadas y marchas por las principales arterias de la ciudad. La presión popular se intensifica con el pasar de las horas y algunas estaciones del metro son penetradas por manifestaciones que destruyen torniquetes, tiendas comerciales, cajeros e incluso inmobiliario de vagones. Las fuerzas represivas se ven superadas, concentrando sus acciones sólo en aquellos lugares próximos a la autoridad de gobierno.

Por la noche la movilización popular se vuelve un fenómeno de masas y transversalmente inorgánico, afectando a todo el radio urbano de Santiago. Miles de personas y grupos de vecinos se agrupan de manera pacífica, en esquinas y barrios de distintos estratos sociales. Comienzan los cacerolazos y los focos de barricadas se multiplican por diversos puntos de la capital.

El gobierno adopta un discurso deslegitimador, de violencia criminal, dada la destrucción del mobiliario público. No obstante, los principales barrios y comunas de Santiago son ocupados por vecinas, vecinos y familiares que empatizan con la protesta. "No eran treinta pesos, eran treinta años", es la consigna que sintetiza dicha horizontalidad y masiva legitimidad. Las columnas de humo y barricadas también se multiplican. El edificio de la compañía eléctrica de capitales multinacionales italianos, ENEL, arde en llamas. Cerca de las 23 horas aparecen las primeras imágenes de estaciones de metro completamente incendiadas, al igual que tiendas comerciales y buses de locomoción colectiva. El gobierno decreta Estado de Emergencia y designa un Jefe de Defensa Nacional a cargo de las Fuerzas Armadas y de Orden Público. Los militares regresan al espacio público después de tres décadas.

Al día siguiente las manifestaciones en la vía pública se agudizan. Multitudinarios cacerolazos intergeneracionales toman el control de la ciudad, paralizando el circuito de transporte y la comunicación urbana por todo Santiago. La prensa intenta criminalizar las acciones de protesta por actos vandálicos, no obstante, la movilización crece cuantitativa y cualitativamente. 
También comienzan los primeros saqueos a supermercados y grandes tiendas comerciales, los cuales se multiplican con el pasar de las horas y los días. El gobierno, a las 18:00 horas, anuncia toque de queda desde las 22hrs. Sin embargo, en las ciudades de Arica, Iquique, Antofagasta, Calama, Coquimbo, Valparaíso, Rancagua, Talca, Concepción, Temuco, Osorno, Ancud, Coyhaique, Punta Arenas, entre otras (ver imagen 2), las movilizaciones se amplifican.

\section{Imagen 2}

Mapa nacional del proceso de movilización social
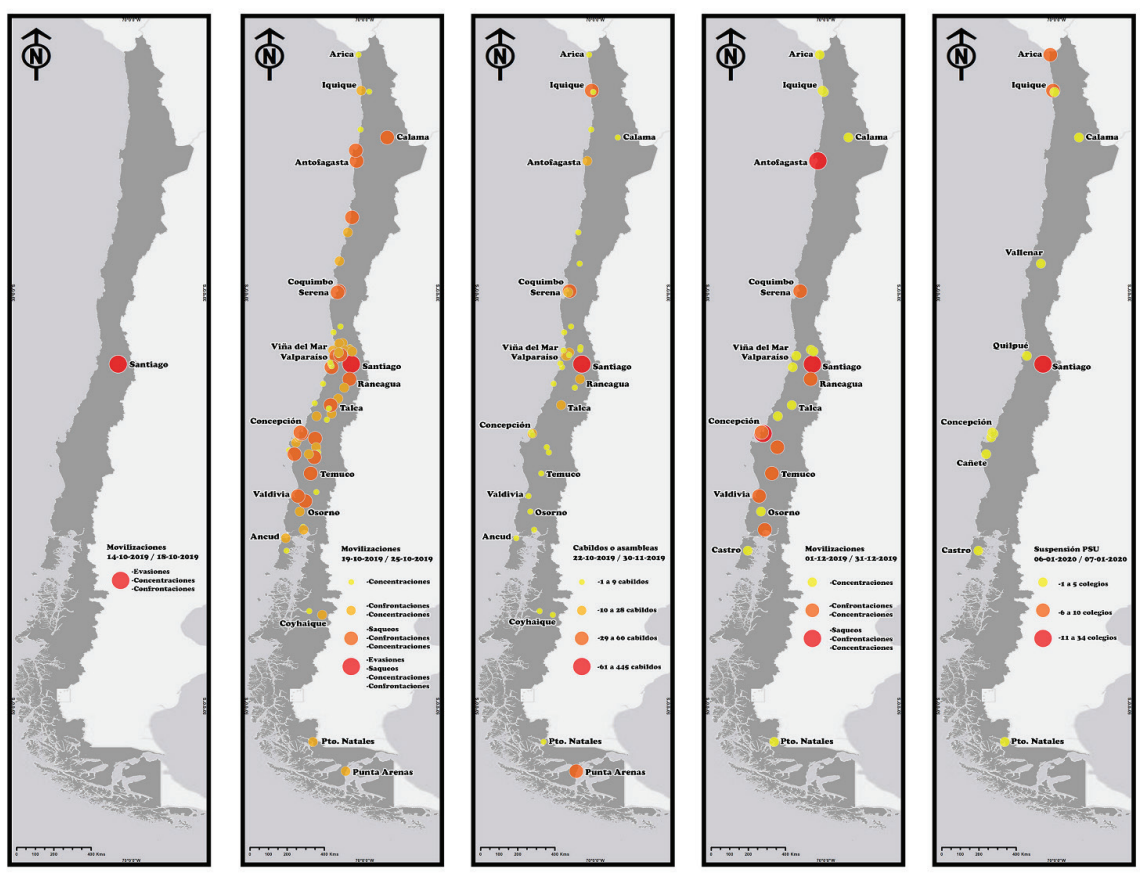

Fuente: Elaboración propia

A raíz de los saqueos en comunas periféricas de Santiago, el 20 de octubre aparecen las primeras tres víctimas fatales. En la misma noche del sábado, el presidente Sebastián Piñera declaró la guerra a un "enemigo poderoso", afianzando el antagonismo radical entre la movilización popular 
espontánea y la irrisoria respuesta del gobierno. Tras el tercer día del toque de queda, comienza a sonar "El derecho de vivir en paz", una de las canciones más significativas del cantautor popular Víctor Jara, asesinado en dictadura. En redes sociales se muestran y amplifican diferentes performances musicales en las ciudades de todo el país, condensando el sentido de la protesta social en la canción de Víctor Jara.

El viernes 25 de octubre más de dos millones de personas se reunieron en el centro de Santiago. En todo el país, otros cientos y miles se manifiestan para impugnar al gobierno y abrir una agenda social: nueva constitución, no más AFP (Administradora de Fondos de Pensiones), salud y educación de calidad. Al día siguiente, el gobierno suspendió el toque de queda como signo de negociación, aunque las protestas prevalecieron principalmente a través de la destrucción del mobiliario urbano y el enfrentamiento directo contra las fuerzas de orden público. De esta forma, el gobierno anunció un nuevo paquete de medidas sociales y asignaciones presupuestarias en materias de pensión, salud y servicios básicos. Sin embargo, las movilizaciones comienzan a adquirir nuevos rasgos de organización a través de asambleas territoriales y cabildos autoconvocados, los cuales fluctúan entre 800 y 1.000 , en cuarenta ciudades de Chile (ver imagen 2).

El viernes 8 de noviembre Gustavo Gatica, estudiante de psicología, es herido de gravedad en ambos ojos. Este hecho, que significó la ceguera total del estudiante, marcó un punto de inflexión. Según antecedentes del Instituto de Derechos Humanos (INDH) y del Colegio Médico (COLMED), al 10 de noviembre existían cerca de 200 personas con daños oculares, 5000 personas detenidas, 1700 heridas de gravedad y 22 muertos.

Producto de la intensa movilización popular, el 15 de noviembre las principales cúpulas partidarias, representantes de las derechas, el centro y una parte de la izquierda, firman el Acuerdo por la paz social y una nueva constitución. Ese viernes por la mañana, la "Plaza Italia" amanece cubierta de blanco. ${ }^{1}$

1 Cabe indicar que la Plaza Italia es el centro neurálgico de las protestas en Santiago y tal vez del país, siendo un lugar estratégico y simbólico de la reapropiación urbana del proceso de movilización ascendente. En este centro urbano de bifurcación, que jerárquica y socialmente separa al sector oriente rico y poniente pobre de la ciudad, emana buena parte del accionar político que mantiene activa a la movilización y su proceso de negociación. Plaza Italia es hoy llamada Plaza Dignidad y geopolíticamente se convierte en el centro de la territorialidad ascendente del malestar y lugar emblemático de la organización que resiste al accionar represivo del Estado como Zona Cero. En términos simbólicos, existe un consenso espontáneo de las narrativas de la protesta en rebautizar su nombre como Plaza de la Dignidad. 
En diciembre, la Cámara de Diputados aprueba el proyecto "ley antisaqueos" para modificar el Código Penal y tipificar como delito la alteración de la paz pública. Pese a toda la arremetida por criminalizar la protesta, esta última sigue multiplicándose y consolidando a lo largo y ancho del territorio. El viernes 20 de diciembre, el Intendente de la Región Metropolitana decide copar policialmente la "Plaza de la Dignidad", situación que derivó en nuevas movilizaciones, además de la acusación constitucional contra el Intendente, quién finalmente salió impune.

Para finales del 2019 y comienzos del 2020, si bien la protesta evidencia ciertos rasgos de desgaste, los cabildos y asambleas territoriales siguen siendo una de las expresiones políticas activas de mayor importancia a escala nacional. De hecho, Zambrano y Huaiqui (2020), a partir de una plataforma virtual autoconvocada, evidenciaron que, entre el 22 de octubre y el 30 de noviembre, se informó un total de 1047 cabildos y asambleas en Chile. En suma, el mapa actual de la movilización social no sólo permite develar los impactos diferenciados del proceso de neoliberalización chileno, sino también las múltiples respuestas y manifestaciones diversas de reapropiación territoriales que cristalizaron la geografía de un nuevo terreno político en todo el país.

\section{Hacia la ruptura del consenso neoliberal, la politización de lo social y el fortalecimiento del poder local}

Un primer aspecto que permite entender la rebelión social es la ruptura del consenso neoliberal. Pero, ¿cómo se construyó este consenso y cuáles son sus características operacionales esenciales? Pues bien, con el golpe cívico-militar de 1973 se abrió un inédito camino de neoliberalización y desintegración social, donde gran parte de los sectores populares fueron convertidos en masa marginal, relegados a habitar en las periferias de las ciudades, y constituidos como ciudadanos por medio del consumo y del endeudamiento (Vargas, 2019). Lo paradójico de esta ciudadanización vía consumo es que no se logró profundizar la ciudadanía liberal. Se trató de un largo proceso histórico de desciudadanización estructural, debido a la pérdida de derechos sociales y sindicales. Precarización y flexibilidad laboral, competencia extrema, privatización de derechos, mercantilización de la vida social e inseguridad social, trazan la vida social en el Chile neoliberal. 
Desde la década del noventa en adelante se materializa el consenso neoliberal entre la elite política y la elite económica. El proyecto de la "Concertación de Partidos por la Democracia" profundizó la neoliberalización impuesta en dictadura por dos vías principales: socavó el Estado en su forma subsidiaria y restringió los contenidos de la incipiente democracia liberal. Esta profundización se observa en la particular y progresiva realización del principio de mercantilización de derechos sociales. Veamos algunos ejemplos. Con el código de aguas de 1981 se faculta al Estado para conceder derechos de aprovechamiento de aguas de manera gratuita y a perpetuidad. En el gobierno de Frei (1994-2000), se privatizan, total o parcialmente, las empresas públicas de gestión del agua. En 1980 se crean las Administradoras de Fondos de Pensión (AFP) como un sistema de capitalización individual. A diciembre de 2018, el 50\% de los 684 mil jubilados y jubiladas obtuvieron una pensión inferior a $\$ 151000$ pesos chilenos. Incluso, en el tramo de aquellas personas que cotizaron entre 30 y 35 años, el 50\% recibió una pensión menor a \$296332 (ver https://bit.ly/3gk7IA4). Esto considerando que el sueldo mínimo al 01 de marzo del 2020 es de $\$ 320$ 500. En el sector educación universitaria, el año 2005 se crea el Crédito con Aval del Estado (CAE) para facilitar el acceso. En el año 2011, un 40\% de jóvenes proveniente de sectores de bajos ingresos económicos, ingresa a la enseñanza superior. Más del 70\% de los estudiantes se endeuda. Inclusive 2 de cada 3 estudiantes deserta por razones financieras (Páez, 2017). En el campo de la salud, en el año 2005, se implementa el Plan de Atención Universal con Garantías Explícitas (AUGE) para garantizar la atención de la ciudadanía en determinadas enfermedades. Cuando el sistema público no tiene cobertura de atención, se deriva la atención al sector privado. Esto tuvo como consecuencia el traspaso de US\$ 6809 millones de fondos públicos a la red privada de salud, la cual aumentó su capacidad en un 20\% entre 2005 y 2011 (Goyenechea \& Sinclaire, 2013).

De este modo, el principio subsidiario del Estado supone un rol secundario del aparato estatal respecto del mercado, como lugar privilegiado para satisfacer necesidades humanas. El Estado interviene cuando el privado no puede hacerlo o no le interesa (Guardia, 2015). La desprotección del Estado frente a la ola privatizadora sobrecargó el bolsillo familiar de los chilenos, lo que se tradujo en el año 2011, en una de las crisis sociales de mayor magnitud del último tiempo. Así, la crítica a la mercantilización de la educación, los intereses territorial-ambientales, regionales, además de la legitimidad la 
demanda etnonacional mapuche (Penaglia, 2016), son algunas de las expresiones territoriales de mayor recurrencia en el proceso.

La democracia mínima (Guardia, 2015) del Estado subsidiario promovió la despolitización y neutralización de la conflictividad social, separando radicalmente la política de su base social y construyendo gobiernos "técnicos". Con ello se observó una baja sostenida de participación ciudadana en los distintos procesos electorales, derivando en una democracia de carácter semi-soberana (Hunneus, 2014). Se construye así, una población espectadora de las políticas públicas, solo reservada socialmente a la esfera de lo familiar.

Durante los diecisiete años de autoritarismo ultraliberal (1973-1990), las históricas redes y estructuras partidarias de la izquierda chilena cambiaron a partir de un conjunto de dispositivos coercitivos que alteraron estructuralmente la forma de entender la política. La dictadura chilena no sólo aplicó la represión y proliferación del terror, también se esmeró en construir consensos y disputar el sentido común para un nuevo proyecto de sociedad (Valdivia et al., 2012; 2015). En este contexto, el espacio municipal y la gestión territorial verticalizada del Estado en regiones, se volvió parte del núcleo del accionar político del régimen autoritario. Se creó una nueva representación de la política entendida como participación familiar, local y comunitaria para validar al régimen (Quiroz, 2018; Valdivia et al., 2012).

La municipalización inscrita en el proceso de regionalización implicó una nueva división política administrativa de las unidades subnacionales generando mayores niveles de coordinación, recursos y competencias (Quiroz, 2018). De forma paralela, el nuevo Estado regional se jerarquizó militarmente y se fortificó mediante el funcionamiento de las Secretarías Regionales de Planificación (SERPLA), pues ellas debían promover y activar la planificación territorial del nuevo modelo económico para Chile. A partir de este estricto control militar y de las primeras reformas neoliberales, se desplegó el traspaso de importantes recursos y redes técnicas hacia los territorios locales. Esto permitió el reclutamiento de una nueva elite política que no solo se localizó, sino que se expandió desde los municipios a otros circuitos políticos institucionales.

La esfera municipal se volvió el principal mecanismo de integración, despolitización y validación social del régimen (Valdivia et al., 2012). Las municipalidades y sobre todo las y los alcaldes del periodo adquieren una importante relevancia política a nivel local y regional, al ejecutar programas de empleo mínimo, entrega de viviendas, creación de actividades deportivas 
y recreación familiar, capacitación para los más pobres, además del traspaso de servicios como la salud y la educación, entre otros. Estas políticas neoliberales-corporativistas decantaron en un importante núcleo de desigualdades y conflictos en ascenso en los sectores populares. A la vez fueron el mecanismo para integrar y validar al régimen autoritario entre los más pobres y sectores medios, pues así se fortalecieron redes y organizaciones con participación de baja intensidad y alta dependencia de la estructura municipal.

Según Valdivia (2015) la reforma de 1979 fue el dispositivo que entrelazó íntegramente el neoliberalismo, el corporativismo militar y el gremialismo (las tres corrientes que lideraron el régimen autoritario). El accionar del municipio delegó una serie de servicios públicos a firmas privadas, reestructurando al Estado subsidiario de gestión local focalizada en la pobreza. De este modo, la municipalización es una pieza clave para entender el carácter político del régimen y el despliegue territorial del consenso neoliberal a escala local-nacional.

Por su parte, la situación singular que se abre en Chile tras la rebelión social de octubre invita a pensar la movilización como una ruptura radical del propio consenso neoliberal. La protesta y la reapropiación política del espacio urbano ha sido la expresión de una acumulación de malestar social no procesado, que demanda lo que el propio consenso negó. No estamos frente a una crisis económica del neoliberalismo chileno. Se trata de una crisis de la subjetividad neoliberal, de un rechazo político y social a las políticas de austeridad y de abandono del Estado, pero además de una crítica radical al sistema político institucional.

Un segundo aspecto que se observa en este proceso es la politización de lo social. Una de las principales consecuencias de la democracia semisoberana fue una fuerte fractura social. Desde el 2011, hemos visto cómo la crisis política amenazaba con destruir la legitimidad de las instituciones, y en efecto, las movilizaciones y protestas hicieron estallar la política. Varias encuestas dan cuenta que el sistema de partidos y las instituciones, así como las coaliciones políticas ubicadas en el oficialismo y la oposición mantienen tasas considerables de desaprobación (Salazar, 2019). Estamos frente a un desplome de la legitimidad de la política institucional. Nunca, desde la vuelta a la democracia, un presidente de la República ha tenido una aprobación de un $6 \%$ y un $82 \%$ de desaprobación de la gestión del gobierno.

Cabe preguntarse en qué sentido nos encontramos frente a un proceso de politización de lo social. Para responder a esta pregunta es posible identi- 
ficar al menos tres elementos. Primero, no se trata de politización en el sentido formal institucional clásico, pues, antes de la rebelión social es posible observar bajas tasas de participación en partidos políticos. La politización de la que hablamos acá, más bien, referencia un tipo de práctica activa y de participación intensiva en las diversas manifestaciones políticas (asambleas, cabildos, concentraciones en plazas públicas, marchas, enfrentamientos con la fuerza pública), que demandan múltiples necesidades, sin reducirse a una de estas. Nos referimos a demandas que van desde pensiones dignas, salud y educación de calidad, salario mínimo digno; hasta una nueva constitución y Asamblea Constituyente. Todo ello nos refleja un clamor social por una nueva norma de convivencia que no esté mediada, ni comandada, por la orientación a la ganancia de grandes capitales internacionales y nacionales. Es decir, estamos frente a un interés real por la política, y no un interés en los partidos políticos por su incapacidad para representar lo social. Esto es bastante claro al mirar la información del Servicio Electoral de Chile (SERVEL). Este servicio muestra que al 31 de enero del 2020 existe un total de 1014968 afiliados a partidos políticos, los cuales representan tan solo un $7,2 \%$ del total de población en Chile en condición de votante. Del mismo modo, para el rango etario entre 18 y 24 años, estos representan un $0,6 \%$ del total de población votante, específicamente 82417 personas.

Segundo, el neoliberalismo ha generado un proceso de "desciudadanización", pues en el contexto de la arremetida del capital contra el trabajo, se pierde uno de los momentos constituyentes claves en el siglo XX, los derechos sociales. Así, la tendencia general a inicios del siglo XXI por mayor seguridad social frente a un Estado subsidiario debilitado, tensionan la propia agenda del neoliberalismo. Dado el gran impacto institucional de la rebelión social, el gobierno de Sebastián Piñera se vio obligado a abrir un proceso consultivo para cambiar la constitución. Por tanto, la politización que se abrió el año 2011 con el movimiento estudiantil y que se diversificó con las protestas de movimientos regionales del 2012, las multitudinarias marchas del 2016 convocadas por la Coordinadora No + AFP, las crecientes marchas del movimiento feministas del 2018; ha venido ampliando los límites de lo cuestionable, al fisurar profundamente la agenda política neoliberal.

Tercero, una característica singular que ha tenido la rebelión social chilena ha sido la destrucción de ciertos símbolos de la dominación política, social, cultural y económica, como parte del proceso de reapropiación subalterna del espacio urbano. Así, se afectaron locales comerciales (farmacias, 
comida rápida, concesionarias de venta de automóviles, hoteles), estatuas destruidas, intervenciones públicas, murallas intervenidas, cambios creativos de los nombres de plazas, entre otros; lo que expresa una politización del conflicto que va más allá de lo que una vía formal institucional puede procesar. Es, en definitiva, la dimensión conflictiva que expresa el registro político en lo social, esto es: anormalidad y desestabilización.

Finalmente, y relacionado directamente con lo anterior, aparece un tercer aspecto a teorizar sobre la rebelión social en las ciudades: el lugar de lo municipal, del gobierno de la ciudad, como espacio legitimado. Como sostuvimos más arriba, con el regreso a la democracia, los municipios permanecieron normativamente con las mismas facultades heredadas, siendo naturalizado un orden público territorial desafectado de derechos políticos deliberativos y universales. La gestión comunal continúo siendo dividida social y geográficamente en municipios gerentes y municipios precarizados. Si bien las y los alcaldes fueron electos democráticamente, la estructura clientelar diseñada en el periodo dictatorial se sistematizó y expandió políticamente de manera transversal. Sin entrar en disputa con los principios autoritarios de la alcaldización y procurando una administración no conflictiva del neoliberalismo, los municipios paulatinamente fueron tomando posiciones de disidencia, pero, en la mayoría de los casos, siempre al amparo de redes partidarias y lógicas centralistas, funcionales a las prácticas de los partidos políticos (Valdivia, 2015, p. 130).

Pese a estas contradicciones, en determinadas circunstancias las autoridades locales entraron en tensión con sus propios partidos y directrices de las coaliciones de gobierno (Pérez, 2020). Al respecto, la Asociación Chilena de Municipalidades anunció el primer plebiscito constituyente, desbordando los tiempos y la agenda del propio Ministerio de Desarrollo Social. Esto se concretó en 226 comunas de todo el país, donde más de 2 millones de personas se manifestaron a través de voto voluntario de manera virtual y presencial. El 91,3\% de las personas están a favor de una nueva Constitución y un $8,7 \%$ en contra. Este hito marcó la pauta y urgencia del proceso constituyente. Sin embargo, más allá de la coyuntura, dicha disidencia esporádica de los municipios no ha modificado estructuralmente el pacto comunal autoritario, es decir, se siguieron afianzando las redes clientelares y la respectiva alcaldización de la política en las ciudades.

En este inusual fenómeno, las y los alcaldes, de todo el espectro ideológico nacional, figuran como los políticos mejor evaluados. Ello muestra 
una posición estratégica de las autoridades locales, en tanto reconocimiento y proyección social de las y los ciudadanos. Cabe preguntarse si ¿pueden ser las y los alcaldes de derecha representantes genuinos del malestar social reciente? En la víspera del proceso constituyente varios alcaldes de derecha en Santiago, tales como Germán Codina en la comuna de Puente Alto y Rodolfo Carter en La Florida, pasaron a ser parte activa de las movilizaciones como protectores de los vecinos y locales, siendo capaces de articular y movilizar redes de apoyo a un gobierno central intransigente.

Hoy en día la principal carta presidencial de la derecha es Joaquín Lavín, un alcalde de una de las comunas más ricas del país y uno de los principales promotores del neoliberalismo chileno durante las últimas décadas. Esta tendencia hacia la derechización y municipalización ha ido consolidándose paulatinamente a partir de las posiciones asumidas por la Asociación Chilena de Municipalidades en el debate constitucional y en las formas de procesamiento del conflicto.

¿Cuál fue entonces la ruptura del pacto comunal en democracia? Hay un hito que marca una ruptura fundamental del pacto comunal autoritario, que se reactiva a partir de la rebelión de octubre. Se trata de la Farmacia Popular Ricardo Silva Soto, inaugurada en 2015 en la comuna de Recoleta. Un dispositivo municipal que, si bien continuó la misma alcaldización al potenciar la figura del alcalde Daniel Jadue (Partido Comunista de Chile), invirtió radicalmente el contenido y la forma de politización comunal. En efecto, esta política municipal rápidamente se legitimó a nivel nacional, cuestionando abiertamente los principios del modelo neoliberal. Jadue transformó una demanda social en un órgano institucional de pretensión popular con altos grados de legitimidad. Es decir, un órgano disponible para disputar la hegemonía del consenso ultraliberal con grados de paridad significativos en un territorio (Quiroz, 2015).

La experiencia de Recoleta no solo pone en entredicho las lógicas de precarización de la salud y su impunidad financiera en la distribución de medicamentos, sino también revela el contenido de lo público, en tanto distribución y acceso universal de bienes comunes a escala nacional. En ese contexto, dicha experiencia permitió a miles de chilenas y chilenos, en diferentes comunas del país, acceder a medicamentos inescrupulosamente usureros. En estos últimos cinco años (2015-2020), ópticas y farmacias populares, librerías municipales, supermercados comunitarios, entre otras iniciativas, constatan la pérdida del consenso neoliberal y un nuevo reperto- 
rio de la gestión municipal de las ciudades en Chile, en abierta tensión con el antiguo enclave clientelar despolitizado.

En consecuencia, la gestión municipal de Recoleta liderada por Daniel Jadue, simbólica y materialmente, se convirtió en un laboratorio del disenso neoliberal en Chile: se expandieron y siguen expandiendo aquí un conjunto de experiencias y prácticas que re-significaron el espacio público en que fue pensada la administración municipal en dictadura y se re-configuró la articulación social, en tanto relaciones políticas de abertura con la comunidad local. Es así como se explica y contextualiza la aparición de espacios escolares reutilizados temporalmente vía talleres comunitarios, la ampliación de cursos abiertos para la comunidad, la extensión de prácticas deportivas para la formación de sectores medios y populares, la aparición de co-gobiernos escolares, el fortalecimiento de las condiciones laborales de los profesores de los establecimientos públicos, la creación de una Universidad Abierta y una Librería Popular que nuevamente sobrepasó la demanda y organización comunal.

Lo que nos interesa destacar es que, desde Recoleta, se abrió una gestión política territorial local inédita hasta este momento, disponible para disputar el escenario neoliberal y abierta para crear condiciones de representación local capaces de irrumpir frente las resistentes prácticas políticas tradicionales, por lo general, repleta de autoritarismos presidencialistas o competencias parlamentarias funcionales al estatus quo. ¿Será que los municipios tienen un papel estructural en la política después de la rebelión social? ¿Será que el malestar se conecta por una nueva morfología territorial que tiende a politizar la escala comunal?

\section{Conclusiones}

Existe un relativo consenso con relación a que la rebelión social de octubre reveló, por una parte, la profunda crisis del sistema de representación política, y, por otra, la ampliación de la conciencia social sobre las injusticias y desigualdades provocadas por la neoliberalización de la sociedad chilena, y que ha sido desnudada por los diversos ciclos de movilización que le antecedieron (Mayol, 2019; Folchi, 2019; NEMESIS, 2019; Salazar, 2019; Araujo, 2019). El análisis de coyuntura de la rebelión social que hemos ensayado, da cuenta de un fiel testimonio del agotamiento de la neoliberalización chilena concentrada en la desregulación estatal, en la pérdida de dere- 
chos sociales y sindicales; y en la dominancia del patrón de acumulación, donde el capital financiero es liberado de cualquier tipo de garantía social para revalorizarse.

Lo nuevo de la rebelión social se observa en la intensidad de las luchas, la amplitud y diversificación de formas y contenidos de usos políticos del espacio urbano, en centralidades urbanas y barrios populares, y su permanencia en el tiempo-espacio. Ello evidencia un proceso de reapropiación subalterna de la articulación social en la ciudad, pues, no solo aumentó el número de personas movilizadas, sino también el número de ciudades y territorios que se levantaron al unísono.

La posibilidad de un plebiscito para la elaboración de una nueva Constitución de la República, así como el ejercicio de votación realizado por la Asociación Chilena de Municipalidades, es un fenómeno nuevo en toda la historia política de Chile. Esta cuestión muestra la necesidad de refundación del Estado subsidiario como condición necesaria para revertir la profundización del proceso de neoliberalización a escala nacional. Esta demanda se ha convertido en una de las principales referencias de politización de la sociedad chilena, lo que implica necesariamente el cambio de las bases del acuerdo nacional de convivencia.

Las demandas ciudadanas manifiestan la necesidad de construir nuevas formas de hacer política. De hecho, uno de los temas más novedosos e interesante que constatamos es el florecimiento de los espacios autoconvocados que han sido masivos y diversos en las ciudades del país. Allí se viene fortaleciendo el poder local desde lo social, discutiendo los temas generales del país y su futuro, lo cual se ha conjugado con temáticas específicas, como son los problemas medioambientales, las infancias, la plurinacionalidad, los feminismos, y el proceso constituyente (Zambrano \& Huaiqui, 2020). También es inédita la gestión política local-comunal de Recoleta en la ciudad de Santiago, que disputa la forma tradicional de hacer política local. Frente a un escenario eventual del proceso constituyente, se plantea el desafío de disputarlo desde la esfera comunal-vecinal, en tanto, dinámica de integración social deliberativa que incluya las demandas estructurales de la ciudadanía, y que ponga en el centro del análisis las escalas geográficas del poder (Quiroz \& Contreras, 2019).

En adelante, podrá evaluarse si a escala nacional e institucional la politización de lo social y sus expresiones locales, reconstruyen una interdependencia social posneoliberal. Este es un tema poco explorado en la literatura 
que ha venido ensayando y debatiendo los aspectos estructurales y coyunturales de la rebelión social, que aún está en desarrollo. Por ello, serán necesarias nuevas investigaciones sobre los alcances y limitaciones de la ruptura del consenso neoliberal, la politización de lo social y la disputa municipal por nuevos sentidos de autoridad y legitimidad que se articulen a la escala nacional. Sin duda, este escenario coloca nuevos desafíos económicos, políticos y sociales para que la consigna popular: "hasta que la dignidad se haga costumbre en Chile", sea un horizonte significativo, concreto y efectivo para la lucha política, social y territorial.

\section{Bibliografía}

Araujo, M. (2019). Hilos tensados. Para leer el octubre chileno. USACH.

Delgado, F., \& Maugard, M. (2018). Movilización y organización popular en dictadura: las jornadas de protesta nacional en Arica (1980-1986). Izquierdas, 39, 34-56. https://bit.ly/328b1FC

De La Maza, G., \& Garcés, M. (1985). La explosión de las mayorías. Protesta Nacional 1983-1984. Educación y Comunicaciones.

Folchi, M. (2019). Chile despertó. Lecturas desde la historia del estallido social. Universidad de Chile.

Garcés, M. (2019). Octubre de 2019: Estallido social en el Chile neoliberal. https:// bit.ly/2Qdm3DZ

Goyenechea, M., \& Sinclaire, D. (2013). Las rentables heridas de la salud chilena. CIPER Chile. https://bit.ly/34kuKoj

Grez, S. (2019). Rebelión popular y proceso constituyente en Chile. En M. Folchi, (Ed.), Chile despertó. Lecturas desde la historia del estallido social (pp. 13-20). Universidad de Chile.

Guardia, A. (2015). La experiencia democrática chilena: de sus fundamentos y su economía política (1990-2009). Ed. Fondo de Cultura Económica.

Matus, M. (2019). Desigualdad: la grieta que fractura la sociedad chilena. En M. Folchi (Ed.), Chile despertó. Lecturas desde la historia del estallido social (pp. 59-69). Universidad de Chile.

Mayol, A. (2019). Big Bang. Estallido social 2019. Modelo derrumbado, sociedad rota, política inútil. Catalonia. 
Mayol, A., \& Azócar, K. (2011). Politización del malestar, movilización social y transformación ideológica: el caso "Chile 2011”. POLIS Revista de la Universidad Bolivariana, 10(30), 163-184.

Milos, P. (2015). Las protestas de abril de 1957. https://bit.ly/2COetN5

Nemesis (2019). Violencias: conceptos y materialidades contemporáneas. Revista de Ciencias Sociales, 15. Universidad de Chile.

Páez, A. (2017). ¿Por qué el CAE es un mecanismo de (desposesión) expropiación financiera? El Mostrador. https://bit.ly/2QevjYp

Penaglia, F. (2016). Subversión del orden transicional. Del oscurantismo posdictatorial a la esperanza. El Buen Aire.

Pérez, A. (2020). ¡Esto no será un sindicato de alcaldes, pero...! Repensando la intermediación local-nacional a través de la historia de la Asociación Chilena de municipalidades (1993-2005). Izquierdas, 49, 365-384. https:// bit.ly/3j06315

Quiroz, R. (2015). Jadue, la geopolítica y la imaginación comunal. https://bit. ly/2QdmH4f

Quiroz, R. (2018). Política y geopolítica en el proceso de regionalización en el Chile autoritario (1973-1990). Revista Brasileira de Geografía, IBGE, 63(2). https://doi.org/10.21579/issn.2526-0375_2018_n2_52-63

Quiroz, R., \& Contreras, P. (2019). ¿Una vía comunal constituyente? Notas para una apropiación territorial del proceso constituyente. La raza cómica. https://bit.ly/2CLiAJA

Salazar, G. (2006). La violencia política popular en las grandes alamedas. La violencia en Chile 1947-1987 (Una perspectiva histórico popular). LOM Ediciones.

Salazar, G. (2019). El 'reventón social' en Chile: una mirada histórica. https://bit. ly/3gj0vQP

Valenzuela, E., Penaglia, F., \& Basaure, L. (2016). Acciones colectivas territoriales en Chile, 2011-2013: de lo ambiental-reivindicativo al autonomismo regionalista. EURE, 42(125), 225-250. http://dx.doi.org/10.4067/S025071612016000100010

Valdivia, V., Álvarez, R., \& Donoso, K. (2012). La alcaldización de la política. Los municipios en la dictadura pinochetista. Lom.

Valdivia, V. (2015). La democracia dictatorial pinochetista: regionalización y municipalización. Avances del Cesar, 12(12), 171-187.

Vargas, R. (2019). La implosión de la ciudad neoliberal. https://bit.ly/3aIxSeT 
Zambrano, C., \& Huaiqui, V. (2020). Geo Constituyente: cabildos y asambleas autoconvocadas. La recuperación de espacio público por parte de la organización popular. Revista Planeo, 42. https://bit.ly/2QeRwG0

Fecha de envío: 2020/04/I2; Fecha de aceptación: 2020/08/21;

Fecha de publicación: 2020/09/01 